\title{
The cytotoxic and antileishmanial activity of extracts and fractions of leaves and fruits of Azadirachta indica (A Juss.)
}

\author{
Sabrina M. P. Carneiro ${ }^{1}$, Fernando A. A. Carvalho2, 3*, Lorena C. L. R. Santana², Alessian P. L. Sousa ${ }^{1}$, José M. M. \\ Neto ${ }^{1}$, Mariana H. Chaves ${ }^{1}$ \\ Departamento de Química, Centro de Ciências da Natureza \\ 2 Núcleo de Pesquisas em Plantas Medicinais and \\ ${ }^{3}$ Departamento de Bioquímica e Farmacologia, Centro de Ciências da Saúde, Universidade Federal do Piauí, Campus Ministro Petrônio Portela, CEP 64049-550, Teresina \\ - PI, Brasil. Tel.: +55 8632371584.
}

\begin{abstract}
The leishmaniases are severe parasitic diseases that occur worldwide, caused by protozoa of the genus Leishmania. Studies with medicinal plants can lead to a range of possibilities for treating and improving the patients' quality of life. Research on Azadirachta indica fractions and extracts has shown that they have excellent anti-leishmanial activity based on bioactivity-guided fractionation of ethanolic extracts of leaves and seeds and in vitro activity against promastigotes. In this research the most efficient extracts and fractions were selected for tests on intracellular amastigotes of Leishmania amazonensis. The ethanolic extract of the leaves and dichloromethane and chloroform fractions had $\mathrm{IC}_{50}$ values of $38,3.9$ and $1.2 \mu \mathrm{g} / \mathrm{mL}$ for promastigotes and $9.8,1.1$ and $0.6 \mu \mathrm{g} / \mathrm{mL}$ for amastigotes, respectively, at 72 hours. For the ethanolic extract and dichloromethane fraction from nut tegument, the $\mathrm{IC}_{50}$ was 2.7 and $2.1 \mu \mathrm{g} / \mathrm{mL}$ for promastigotes and $0.4 \mathrm{and} 0.6 \mu \mathrm{g} / \mathrm{mL}$ for amastigotes. The cytotoxicity of the fractions presented selectivity that was between 8 to 32 times more toxic to promastigotes and 15 to 72 times to amastigotes than to macrophages. The extracts and fractions from leaves and fruits were more effective against amastigotes, and the fractionation increased activity against both promastigotes and amastigotes, enabling us to obtain potentially active fractions with low toxicity.
\end{abstract}

Key words: anti-leishmanial, Azadirachta indica, cytotoxicity, leishmaniasis, Leishmania amazonensis.

\section{INTRODUCTION}

The leishmaniases are severe diseases that affect the health of more than 12 million people worldwide and 2 million new cases occur each year (Desjeux, 2001; Murray et al., 2005). The disease is prevalent in tropical and subtropical countries and endemic in countries such as Sudan, India, Afghanistan, Syria and Brazil, where it affects people with depressed immune systems, with other infections and the malnourished (SoaresBezerra et al., 2004; Croft et al., 2006). There is limited control of the disease and its incidence is increasing worldwide due to the expansion of international travel, especially among countries that are at war and/or where there are no effective vaccines for humans. Additional problems are the emergence of strains resistant to first line drugs, as well as increasing cases of co-infection with HIV/AIDS (Desjeaux, 2001; Croft et al., 2006; Herwaldt, 2009; Mitropoulos et al., 2010).

Depending on the etiologic agent, the disease can have cutaneous, mucocutaneous or visceral manifestations. A range of Leishmania species can cause disease in humans. The dermotrophic species, such as L. (Leishmania) amazonensis, cause ulcerative skin lesions that are painless, single, multiple or disseminated. L. (Viannia) brasiliensis causes aggressive cutaneous and mucocutaneous lesions that disfigure nasopharyngeal regions. Vicerotropic species, such as $L$. infantum and $L$. donovani, cause visceral leishmaniasis or kalaazar, which is fatal if not treated (Croft and Coombs, 2003; Santos et al., 2008a; Herwaldt, 2009).
These diseases are treated with pentavalent antimonials. $\mathrm{N}$-methylglucamine antimoniate is the main choice and a second option is amphotericin B or pentamidine, if there is resistance to the first drug. Both options have the drawback of severe adverse reactions, with possible development of parasite resistance and exclusive administration in hospitals, which hinders the patient's adherence to treatment (Santos et al., 2008a; Herwaldt, 2009; Mitropoulos et al., 2010).

The presence of unpleasant toxic reactions to conventional medication, coupled with the absence of vaccines and other effective prophylactic measures indicates the need for new therapies that protect against and/or cure leishmaniasis (Croft and Combs, 2003). Natural products of plant origin are potential tools for these discoveries and have been used for centuries to treat empirically parasitic diseases for people around the world, stimulating clinical and laboratory research (Carvalho and Ferreira, 2001; Kaiser et al., 2003).

Azadirachta indica (A. Juss), known as the Indian neem tree, is a species of Meliaceae, abundantly prevalent in tropical countries. It has been used popularly for over 2,000 years for various diseases such as skin ulcers, anorexia, worms, diabetes, fevers and analgesia (Biswas et al., 2002; Schmutter, 2002). It is a medicinal plant that has been widely investigated, and many different therapeutic uses have been noted including: antiinflammatory, antipyretic, hypoglycemic, immunostimulant (Murthy et al., 1978; Biswas et al., 2002), antimicrobial and antiviral (Parida et al., 2002, Schmutter, 2002) 
A few studies have been carried out that have examined the activity of $A$. indica on trypanosomatids, including L. major (Khalid et al., 2005; Mbaya et al., 2010). This information, along with that obtained from Ayurvedic medicine (Biswas et al., 2002), which reports the popular use of the infusion of leaves for skin problems, motivated our study to discover this plant's activity against $L$. amazonensis, an important causative agent of cutaneous leishmaniasis.

This study is the first systematic account of scientific research of this species as a potential therapeutic agent against L. amazonensis.

\section{METHODS}

Plant material

Leaves and fruits of $A$. indica (A. Juss), know as the neem tree, were collected in February and October 2007 respectively at the Center of Agricultural Sciences of the Federal University of Piauí - Teresina-Piauí, Brazil. The species was identified and a sample was deposited at the Graziela Barroso herbarium, UFPI, with the number TEPB 20,970.

Extraction and fractionation

The leaves were dried at room temperature and then ground. The powder $(876 \mathrm{~g}$ ) was homogenized five times consecutively with ethanol and filtered. The solvent was removed by evaporation under reduced pressure, obtaining the ethanolic extract (EtOH-1, $84.1 \mathrm{~g}, 9.6 \%)$. Part of the extract $(74 \mathrm{~g})$ was suspended in a mixture of $\mathrm{H}_{2} \mathrm{O} / \mathrm{MeOH}(1: 5)$ and subjected to a partition with hexane, dichloromethane and ethyl acetate, yielding the respective fractions: Hex-1 (18.0 g, $26.3 \%)$, $\mathrm{CH}_{2} \mathrm{Cl}_{2}-1(19.0 \mathrm{~g}, 27.7 \%)$, EtOAc-1 $(8.0 \mathrm{~g}, 11.7 \%)$ and $\mathrm{H}_{2} \mathrm{O}-1$ ( 23.4 $\mathrm{g}, 34.2 \%)$. The $\mathrm{CH}_{2} \mathrm{Cl}_{2}-1$ fraction was fractionated on a column of silica gel $(180 \mathrm{~g})$, providing the hexane fraction (hex-c, 0.4 $\mathrm{g}, 0.03 \%)$, chloroform $\left(\mathrm{CHCl}_{3}-\mathrm{c}, 5.0 \mathrm{~g}, 43.1 \%\right)$, ethyl acetate (EtOAc-c, $3.0 \mathrm{~g}, 25.9 \%$ ) and methanolic (MeOH-c, $3.2 \mathrm{~g}, 27.6 \%$ ).

The seeds were dried at room temperature and separated into tegument and nut. The nuts $(480 \mathrm{~g})$ were defatted with hexane and then extracted five times with ethanol, providing the oil $(85 \mathrm{~mL}, 17.7 \%)$ and ethanolic extract $(87 \mathrm{~g}, 18 \%)$ respectively. The tegument $(470 \mathrm{~g})$ was extracted five times with ethanol, producing EtOH-t $(20 \mathrm{~g}, 4.24 \%)$. The EtOH-t was fractionated by partition with hexane, dichloromethane and ethyl acetate, yielding the respective fractions: Hex-t (3.9 g, $19.6 \%), \mathrm{CH}_{2} \mathrm{Cl}_{2}$-t $(7.3 \mathrm{~g}, 36.6 \%)$, EtOAc-t $(0.6 \mathrm{~g}, 3.0 \%)$ and $\mathrm{H}_{2} \mathrm{O}-\mathrm{t}$ $(8.17 \mathrm{~g}, 40.8 \%)$.

\section{Chromatography analysis}

The extracts and fractions were analyzed by chromatography on a thin layer of silica gel using the eluents: hexane/AcOEt (8:2) and $\mathrm{CHCl}_{3} / \mathrm{MeOH}$ (9:1). The plates were revealed by spraying with ceric sulfate solution followed by heating.

\section{Spectroscopic analysis}

The spectra of hydrogen nuclear magnetic resonance $\left(\mathrm{RMN}{ }^{1} \mathrm{H}\right)$ were obtained using a Bruker DPX 300 spectrometer operating at $300 \mathrm{MHz}$, using $\mathrm{CDCl}_{3}$ as solvent and tetramethylsilane (TMS) as internal reference.
Parasites

The strains of L. amazonensis (IFLA/BR/67/PH8) were kept at the Laboratory of Antileishmania Activity, the Center for Research on Medicinal Plants, Federal University of Piauí, Teresina (PI) in Schneider's medium (Sigma Chemical, USA) with the addition of $10 \%$ inactivated fetal calf serumFCS (Sigma Chemical, USA), penicillin (100 U/mL) and streptomycin $(100 \mu \mathrm{g} / \mathrm{mL})$ at $26^{\circ} \mathrm{C}$.

Animals

Female BALB/c mice were used for obtaining macrophages that are resident in the peritoneum. The maintenance of the strains followed the norms established and adopted for this purpose. The procedures were approved by the Ethics Committee of the Federal University of Piauí, Number $039 / 2009$.

Drugs

Azadirachtin was obtained from Sigma-USA, a constituent of the species $A$. indica, for testing on L. amazonensis promastigotes. Amphotericin B (Cristália-BRA) was used as a reference drug $(0.2 \mu \mathrm{g} / \mathrm{mL})$ in tests with promastigotes and intracellular amastigotes.

Evaluation of extracts and fractions against L. amazonensis promastigotes

Promastigotes of L. amazonensis $\left(1 \times 10^{6} /\right.$ well) were grown in microplates with 96 wells (TPP - Switzerland) containing Schneider's medium plus the following samples in concentrations ranging from 400 to $0.78 \mu \mathrm{g} / \mathrm{mL}$ in triplicate: EtOH-l, Hex-l, $\mathrm{CH}_{2} \mathrm{Cl}_{2}-\mathrm{l}$, EtOAc-l, $\mathrm{H}_{2} \mathrm{O}-\mathrm{l}, \mathrm{Hex}-\mathrm{c}, \mathrm{CHCl}_{3}$-c, EtOAc -c, EtOH-t, Hex-t, $\mathrm{CH}_{2} \mathrm{Cl}_{2}-\mathrm{t}$, EtOAc -t, $\mathrm{H}_{2} \mathrm{O}-\mathrm{t}$, EtOH-n, Oil-n and azadirachtin diluted in dimethyl sulfoxide (DMSO) to a maximum concentration of $0.5 \%$ in the experimental groups, and Schneider's with $0.5 \%$ DMSO in the control group. After 24,48 and 72 hours of incubation at $26{ }^{\circ} \mathrm{C}$, the number of viable promastigotes from each well was determined in a Neubauer chamber in a blind count, and the mean inhibitory concentration $\left(\mathrm{IC}_{50}\right)$ of each test was calculated.

Evaluation of extracts and fractions against L. amazonensis amastigotes in macrophages

Thioglycollate $(1.5 \mathrm{~mL}$ at $3 \%)$ was administered in the peritoneal cavity of BALB/c mice and after 72 hours the macrophages were elicited by washing the abdominal cavity with $10 \mathrm{~mL}$ of RPMI 1640 medium (Sigma Chemical, USA) at $4{ }^{\circ} \mathrm{C}$. The animal was then shaken, massaging the abdomen and the inoculated volume was aspirated. The aspirate was centrifuged, resuspended in RPMI 1640 medium and the cells counted and placed in culture plates with 24 wells at a concentration of $2 \times 10^{5}$ cells $/ 500 \mu \mathrm{L}$ of medium, containing sterile $13 \mathrm{~mm}$ round coverslips. They were incubated at 37 ${ }^{\circ} \mathrm{C}$ and $5 \% \mathrm{CO}_{2}$ for 2 hours for cell adhesion. The medium was then replaced with $500 \mu \mathrm{L}$ of RPMI 1640 supplemented with FCS, penicillin and streptomycin and incubated for 15 hours. After this period, the RPMI-1640 supplemented medium was aspirated and new media was added containing amastigote-like forms (Teixeira, et al., 2002) at the proportion 
of 8 amastigotes to 1 macrophage in each well. After 4 hours of incubation at $5 \% \mathrm{CO}_{2}, 37^{\circ} \mathrm{C}$, the medium was aspirated to remove the free amastigotes and $1 \mathrm{~mL}$ of supplemented RPMI-1640 was added to the test samples, diluted in DMSO to a maximum concentration of $0.2 \%$ in the experimental groups, and Schneider's with $0.2 \%$ DMSO in the control group and amphotericin B in adequate concentrations. This was incubated for 72 hours, at the end of which, coverslips were removed, fixed with methanol and stained with Giemsa. Three independent experiments were carried out in triplicate for each concentration. For each coverslip, 100 cells were assessed, and the number of infected macrophages and the number of parasites per macrophage were counted. The results, presented as an association index (AI), were obtained by multiplying the percentage of infected macrophages by the mean number of amastigotes per macrophage (Rosa et al., 2003).

\section{Assessment of cytotoxic activity}

The macrophages were elicited from Swiss mice (as described above) and plated at $1 \times 10^{5}$ per well, in sterile 96-well plates for cell culture, in RPMI 1640. After the bonding time, the medium was replaced by RPMI 1640 supplemented with $10 \%$ FCS, penicillin and streptomycin, containing the extracts in concentrations ranging from 100 to $3.12 \mu \mathrm{g} / \mathrm{mL}$ and incubated for 48 hours at $5 \% \mathrm{CO}_{2}, 37^{\circ} \mathrm{C}$. Feasibility was assessed using an ELISA reader, $550 \mathrm{~nm}$ according to the MTT assay (3-[4, 5 dimethylthiazol-2-yl]-2, 5- diphenyltetrazolium bromide) (Reilly et al., 1998). The study calculated the $\mathrm{CC}_{50}$ (toxic concentration for $50 \%$ of cells) by probit analysis and the selectivity index (SI), by the ratio between cytotoxicity
$\left(\mathrm{CC}_{50}\right)$ of host cells $/ \mathrm{IC}_{50}$ of promastigotes and amastigotes in macrophages (Santos et al., 2008b).

Assessment of immunomodulatory activity

Immunomodulatory activity was assessed out in 96-well sterile cell culture plates. The peritoneal macrophages of Swiss mice were plated at $1 \times 10^{5}$ per well in RPMI 1640 medium with the extracts. After $6 \mathrm{~h}$ of incubation at $5 \% \mathrm{CO}_{2}, 37^{\circ} \mathrm{C}$, the supernatant was removed and the production of nitric oxide was obtained indirectly by measuring nitrite with an ELISA plate reader at $550 \mathrm{~nm}$, using the GRIESS reagent (Genestra et al., 2003).

\section{Statistical analysis}

All of the experiments were carried out in triplicate. The cytotoxic and inhibitory concentration at 50\% was calculated using probit analysis (SPSS 13.0). The statistics were analysed using one-way ANOVA followed by Tukey's test, for which $\mathrm{p}<$ 0.05 was considered significant.

\section{RESULTS}

The fractionation of the leaf ethanolic extract (EtOH-1) increased the activity for the partition fractions $\mathrm{CH}_{2} \mathrm{Cl}_{2}-1$ and Hex-l (Table 1). The effect was enhanced with the fractionation of $\mathrm{CH}_{2} \mathrm{Cl}_{2}-\mathrm{l}$, and its activity increased by $70 \%$ in the fraction $\mathrm{CHCl}_{3}-\mathrm{c}$ and $63 \%$ for EtOAc-c on promastigotes. The greater enhancement of the inhibitory effect was also observed for the amastigotes that were internalized in the macrophages,

TABLE I

Activity of Azadirachta indica leaf and fruit samples and azadiaractin in $L$. (L) amazonensis

\begin{tabular}{|c|c|c|c|c|}
\hline \multirow{3}{*}{ Samples } & \multicolumn{4}{|c|}{$\mathrm{IC}_{50}$ value $(\mu \mathrm{g} / \mathrm{mL})^{\mathrm{a}}$} \\
\hline & \multicolumn{3}{|c|}{ Promastigotes } & \multirow{2}{*}{$\begin{array}{c}\text { Amastigotes } \\
72 \mathrm{~h}\end{array}$} \\
\hline & $24 \mathrm{~h}$ & $48 \mathrm{~h}$ & $72 \mathrm{~h}$ & \\
\hline $\mathrm{EtOH}-\mathrm{l}^{\mathrm{e}}$ & $44.0(28.5-67.4)^{\mathrm{b}}$ & $37.0(27.9-48.7)$ & $38.0(30.3-47.8)$ & $9.8(9.0-10.5)$ \\
\hline Hex- $1^{\mathrm{f}}$ & $43.3(22.6-82.2)$ & $15.0(9.7-22.2)$ & $8.5(5.7-11.8)$ & - \\
\hline EtOAc $-1^{g}$ & $\operatorname{In}^{\mathrm{c}}$ & In & In & - \\
\hline $\mathrm{CH}_{2} \mathrm{Cl}_{2}-\mathrm{-1}^{\mathrm{h}}$ & $3.4(2.6-4.3)$ & $3.4(2.9-4.0)$ & $3.9(3.4-4.3)$ & $1.1(1.1-1.2)$ \\
\hline $\mathrm{CHCl}_{3}-\mathrm{c}^{\mathrm{i}}$ & $1.2(0.9-1.7)$ & $1.1(0.8-1.4)$ & $1.2(0.9-1.6)$ & $0.6(0.5-0.6)$ \\
\hline EtOAc $-c^{j}$ & $1.4(0.7-2.6)$ & $2.0(1.2-2.9)$ & $1.4(1.0-2.0)$ & $\mathrm{Nt}^{\mathrm{d}}$ \\
\hline $\mathrm{EtOH}-\mathrm{n}^{\mathrm{k}}$ & In & In & In & $\mathrm{Nt}$ \\
\hline Oil-n $n^{1}$ & In & In & In & $\mathrm{Nt}$ \\
\hline $\mathrm{EtOH}-\mathrm{t}^{\mathrm{m}}$ & $5.8(4.1-7.8)$ & $2.4(1.7-3.2)$ & $2.7(2.0-3.5)$ & $0.4(0.4-0.5)$ \\
\hline $\mathrm{CH}_{2} \mathrm{Cl}_{2}-\mathrm{t}^{\mathrm{n}}$ & $7.8(3.4-17.9)$ & $2.7(1.8-4.1)$ & $2.1(1.6-2.6)$ & $0.6(0.5-0.6)$ \\
\hline Hex- $\mathrm{t}^{\mathrm{o}}$ & In & In & In & In \\
\hline EtOAc $-t^{p}$ & In & In & In & In \\
\hline Azadirachtin ${ }^{q}$ & In & In & In & In \\
\hline
\end{tabular}

a: Concentration that caused 50\% inhibitory growth of promastigotes and intracellular amastigotes; b: $95 \%$ confidence interval; c: inactive at the concentrations studied; $\mathrm{d}$ : not tested; e: ethanolic extract (leaves); f: ethanolic extract (leaves) hexane fraction; g: ethanolic extract (leaves) ethyl acetate fraction; ${ }^{\mathrm{h}}$ : ethanolic extract (leaves) dichloromethane fraction; i: $\mathrm{CH}_{2} \mathrm{Cl}_{2}-\mathrm{I}$ chloroform fraction; ${ }^{\mathrm{j}}$ : $\mathrm{CH}_{2} \mathrm{Cl}_{2}-\mathrm{I}$ ethyl acetate fraction; ${ }^{\mathrm{k}}$ : nut tegument ethanol extract; ${ }^{\text {I: }}$ nut oil; ${ }^{\mathrm{m}}$ : nut ethanolic extract; ${ }^{\mathrm{n}}$ : EtOH-t dichloromethane fraction; ${ }^{\circ}$ : EtOH-t hexane fraction; $\mathrm{P}$ : EtOH-t ethyl acetate; q: Azadirachtin (Sigma - USA). 
where there was a reduction in the survival of the parasite at a concentration of $2.0 \mu \mathrm{g} / \mathrm{mL}$ in $36 \%$ (EtOH-1), 58\% $\left(\mathrm{CH}_{2} \mathrm{Cl}_{2}-1\right)$ and $100 \%\left(\mathrm{CHCl}_{3}-\mathrm{c}\right)$ (Table I, Fig.1).

The ethanolic extract of the tegument (EtOH-t) increased 93\% when compared to EtOH-1, for activity against promastigotes and reduced the survival of amastigotes within macrophages by $87 \%$ at a concentration of $2.0 \mu \mathrm{g} / \mathrm{mL}$. However, the increase in activity was not significant for the $\mathrm{CH}_{2} \mathrm{Cl}_{2}-\mathrm{t}$ fraction against promastigotes and amastigotes (Table I, Fig.1).

There was a reduction of the $\mathrm{IC}_{50}$ for promastigotes with increasing time of exposure for EtOH-l, EtOH- $t$ and Hex-l (Table I).

The fractionation increased the antileishmania activity with low toxicity to mammalian cells and was 8 to 32 times more toxic to L. amazonensis promastigotes and 15 to 72 times more toxic to amastigotes than to the peritoneal macrophages of mice (Table II).

The nitric oxide production by macrophages treated with the extracts and fractions was not significant.

\section{DISCUSSION}

The evaluation of extracts from A. indica (A. Juss) on promastigote forms of $L$. amazonensis followed a fractionation guided by activity. The ethanolic extract of leaves presented high activity as in previous in vitro and in vivo experiments with Trypanosoma brucei (Mbaya et al., 2010) and an $\mathrm{IC}_{50}$ higher than that found by Khalid et al. (2005), with methanolic extract for promastigotes of L. major. The fractionation enhanced the antileishmania effect for both the extracellular form and the macrophage parasites, whereas previous reports found that only the chloroform fraction inhibited the growth of Trypanosoma cruzi epimastigotes and caused ultrastructural changes, such as vacuolation and degeneration of organelles (Yanes et al., 2004). Similarly, the same fraction in this study presented, in addition to excellent antileishmanial activity, morphological changes in the structure of the parasite, visible under light microscopy. This was also reported for L. tropica after incubation with high concentrations of propolis, with cytopathological changes, loss of flagella and rounded cells (Duran et al., 2008).

TABLE II

Cytotoxicity of extracts and fractions from leaves and tegument of Azadirachta indica on murine macrophages and selectivity for the parasite.

\begin{tabular}{cccc}
\hline Plant material & $\mathrm{CC}_{50}{ }^{\mathrm{a}}$ & ${\text { Promastigotes } \mathrm{SI}^{\mathrm{b}}}$ & Amastigotes SI $^{\mathrm{a}}$ \\
\hline $\mathrm{EtOH}-\mathrm{l}^{\mathrm{d}}$ & $56.96(48.7-66.70)^{\mathrm{c}}$ & 1.53 & 5,81 \\
$\mathrm{CH}_{2} \mathrm{Cl}_{2}-\mathrm{l}^{\mathrm{e}}$ & $48.1(35.1-64.9)$ & 14.10 & 43,72 \\
$\mathrm{CHCl}_{3}-\mathrm{c}^{\mathrm{f}}$ & $9.15(7.2-11.7)$ & 8.30 & 15,25 \\
$\mathrm{EtOH}-\mathrm{t}^{\mathrm{g}}$ & $28.9(14.6-34.9)$ & 12.00 & 72,25 \\
$\mathrm{CH}_{2} \mathrm{Cl}_{2}-\mathrm{t}^{\mathrm{h}}$ & $43.54(32.6-58.0)$ & 15.90 & 72,56 \\
\hline
\end{tabular}

a: $50 \%$ cytotoxicity concentration to macrophages; ${ }^{b}$ : selectivity index $\left(\mathrm{CC}_{50} / \mathrm{Cl}_{50}\right)$, a value greater than 20 is specific for the parasite and is not toxic for macrophages; ${ }^{\mathrm{C}}$ : $95 \%$ confidence interval; d: ethanolic extract (leaves); e: ethanolic extract (leaves) dichloromethane fraction; ${ }^{\mathrm{f}}$ : $\mathrm{CH}_{2} \mathrm{Cl}_{2}-\mathrm{I} \mathrm{chloroform} \mathrm{fraction;} \mathrm{g}$ : tegument ethanolic extract; h: EtOH-t dichloromethane fraction.

A

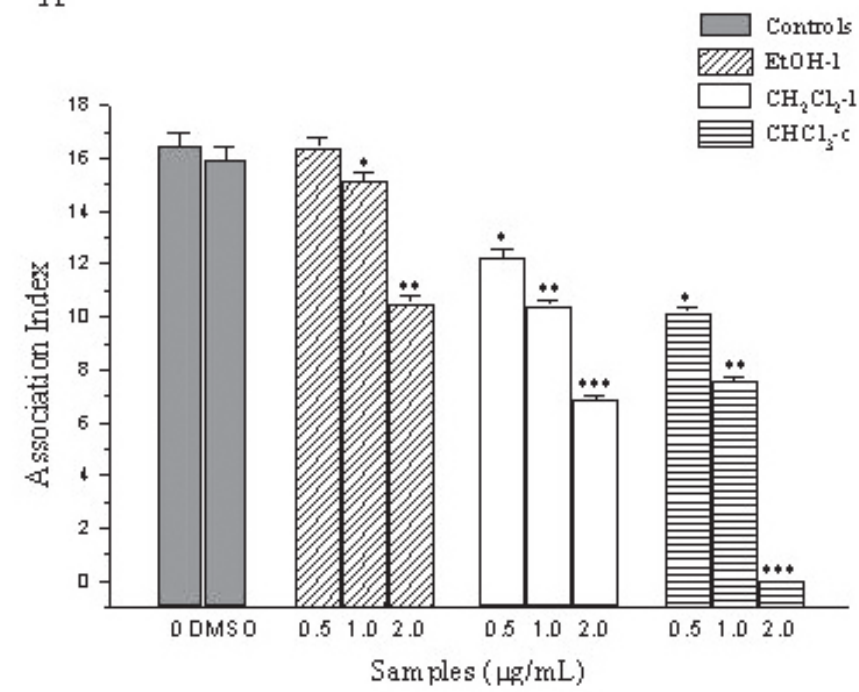

B

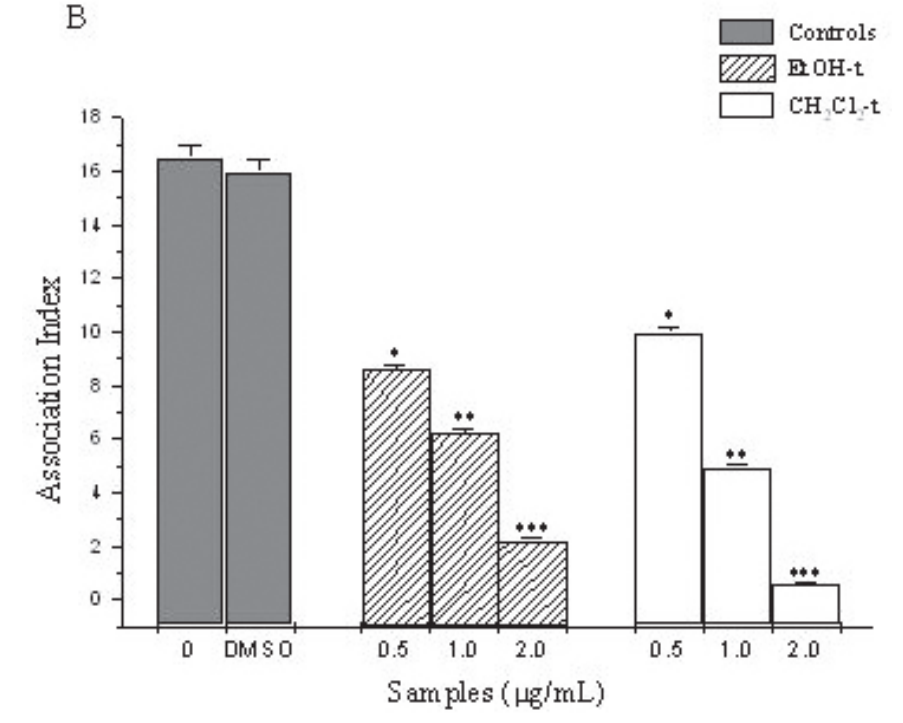

Figure 1: Representation of $A$. indica's effect on the survival of $L$. (L) amazonensis amastigotes internalized in macrophages, after 72 hours of incubation. A: Leaf extracts and fractions. B: Nut tegument extract and fraction. Statistical difference: Tukey test: ${ }^{*} p<0.001$, when compared to the control, ${ }^{* *} p<0.001$, when compared to the $0.5 \mu \mathrm{g} / \mathrm{mL}$ concentration and ${ }^{* * *} p<0.001$, when compared to the $1.0 \mu \mathrm{g} /$ $\mathrm{mL}$ concentrations. Bars show the mean \pm standard error of three experiments carried out in triplicate. 
The thin layer chromatographic profile and the $\mathrm{RMN}{ }^{1} \mathrm{H}$ spectra of the active fractions presented a predominance of terpenoids. The limonoids or tetra-nor-triterpenoids that are quite common in the leaves and fruits of $A$. indica belong to this class of substances (Shumutterer, 2002; Roy and Saraf, 2006).

The active substances appear to be terpenic in origin, since this class of substances is abundantly present in the samples investigated. This class includes an important constituent of neem, azadirachtin, a substance present in all parts of the plant, but in higher concentration in the seed (Forim et al., 2010). Although azadirachtin has induced resistance to the insect vector against reinfection by $T$. cruzi (Garcia et al., 1991), and had activity against Plasmodium falciparum (Tahir et al., 1999), this study showed that this substance was inactive against promastigotes of L. amazonensis. However, other terpenes may be responsible for the anti-leishmanial activity of $A$. indica. Several limonoids present in this species, especially gedunin, dihydrogedunin, nimbolide and nimidin have been tested in vitro against protozoa that cause malaria, such as $P$. falciparum, and presented significant activity (Shumutterer, 2002; Roy and Saraf, 2006). The limonoids 2, 6-dihydroxyfissinolide, fissinolide and 3 $\beta$-acetoxy-6-hydroxy1-oxomeliac-14-enoate, present in Khaya senegalensis had moderate activity against $P$. falciparum and L. major (Khalid et al., 1998).

Despite reports that $A$. indica is capable of activating the immune system to induce the production of interferon-gamma (IFN- $\gamma$ ) and tumor necrosis factor-alpha (TNF- $\alpha$ ) (Mukherjee et al., 1999), cytokines that act in synergy in the activation of macrophages to produce nitric oxide and control the infection by Leishmania (Bogdan et al., 1996), this study did not detect increased levels of nitric oxide, which suggests that this is not the mechanism of action involved.

The species $A$. indica has a number of biological and toxic effects, many of them associated with the presence of salanin, melzatriol, nimbin, cardiac glycosides, tannins, alkaloids and saponins (Biswas et al., 2002; Biu, 2008), but there are no previous reports of cytotoxicity for macrophages.

The extracts and fractions studied showed excellent antileishmanial activity that was unrelated to toxicity, since the best samples had $\mathrm{IC}_{50}<1 \mu \mathrm{g} / \mathrm{mL}$ and a selectivity index greater than 20 , which guarantees safety to the macrophages and specificity to the parasite according to Nwaka and Hudson (2006).

\section{CONCLUSIONS}

The fractionation of crude extract of the leaves of $A$. indica enhances the antileishmania activity in vitro. The diclomethane fraction from the leaves, the ethanolic extract and the dichloromethane fraction from the tegument were considered safe to macrophages and may prove to be potential therapeutic agents to combat leishmaniasis.

\section{ACKNOWLEDGEMENTS}

The authors would like to thank Dr. Eliane de Moraes-Teixeira and Dr. Ana Rabelo at the René Rachou Center for Research, Minas Gerais, Brazil, for their technical and structural support. The support of Conselho Nacional de Desenvolvimento Tecnológico, $(\mathrm{CNPq})$, Capacitação de Aperfeiçoamento de
Pessoal de Nível Superior (CAPES) and Fundação de Amparo a Pesquisa do Estado do Piauí (FAPEPI).

\section{REFERENCES}

BIU AA (2008). Toxicity and anti-coccidial effect of neem Azadirachta indica in chickens. Ph.D. Thesis, University of Maiduguri. pp:15-45.

BISWAS K, CHATTOPADHYAY I, BANERJEE RK, BANDYOPADHYAY U (2002). Biological activities and medicinal properties of neem (Azadirachta indica). Curr Sci 82: 1336-1344.

BOGDAN C, GESSNER A, SOLBACH W, RIJLLINGHOFF (1996). Invasion, control and persistence of Leishmania parasites. Curr Opin Immunol 6: 517-525.

CARVALHO PB, FERREIRA EI (2001). Leishmaniasis phytotherapy. Nature's leadership against an ancient disease review. Fitoterapia 72: 599-618.

CROFT SL, COOMBS GH (2003). Leishmaniasis- current chemotherapy and recent advances in the search for novel drugs. Trends Parasitol 19: 502-508.

CROFT SL, SUNDAR S, FAIRLAMB AH (2006). Drug resistance in leishmaniasis. Clin Microbiol Rev 19:111-126.

DESJEUX P (2001). The increase in risk factors for leishmaniasis worldwide. Trans R Soc Trop Med Hyg 95:239-243.

DURAN D, DURAN N, CULHA G, OZCAN B, OZTAS H, OZER B (2008). In vitro antileishmanial activity of Adana propolis samples on Leishmania tropica: a preliminary study. Parasitol Res 102: 1217-1225.

FORIM MR, SILVA MFGF, CASS QB, FERNANDES JB, VIEIRA PC (2010). Simultaneous quantification of azadirachtin and 3-tigloylazadirachtol in brazilian seeds and oil of Azadirachta indica: application to quality control and marketing. Anal Methods 2: 860-869.

GARCIA ES, GONZALES MS, AZAMBUJA P (1991). Effects of azadirachtin in Rhodnius prolixus: data and hypotheses. Mem Inst Oswaldo Cruz 86: 107-111.

GENESTRA M, ECHEVARRIA A, CYSNE-FINKELSTEIN L, VIGNÓLIOALVES L, LEON LL (2003). Effect of amidine derivatives on nitric oxide production by Leishmania amazonensis promastigotas and axenic amastigotas. Nitric Oxide Biol Ch 8: 1-6.

HERWALDT BL (2009). Leishmaniasis. In: Kasper D L, Fauci A S (eds), Harrison's principles of internal medicine. 16th New york: McGrawHill; pp: 1233-1238.

KAISER O, KIDERLEN AF, CROFT SL (2003). Natural products as antiparasitic drugs. Parasitol Res 90: 55-62.

KHALID FA, ABDALLA M, MOHOMED HEO, TOUM AM, MAGZOUB MMA, ALI MS (2005). In vitro assessment of anti-cutaneous leishmaniasis activity of some sudanese plants. Acta Parasitol Turcica 29: 3-6.

KHALID SA, FRIEDRICHSEN GM, KHARAZMI A, THEANDER TG, OLSEN CE, CHRISTENSEN SB (1998). Limonoids from Khaya senegalensis. Phytochemistry 49: 1769-1772.

MBAYA AW, IBRAHIM UI, GOD OT, LADI S (2010). Toxicity and potential anti-trypanosomal activity of Azadirachta indica (Maliacea) stem bark: An in vivo and in vitro approach using Trypanosoma brucei. J Ethnopharmaco 28:495-500.

MITROPOULOS P, KONIDAS P, DURKIN-KONIDAS M (2010). New World cutaneous leishmaniasis: Updated review of current and future diagnosis and treatment. J Am Acad Dermatol 63: 310-322.

MUKHERJEE S, GARG S, TALWAR GP (1999). Early post implantation contraceptive effects of a purified fraction of neem (Azadirachta indica) seeds, given orally in rats: possible mechanisms involved. J Ethnopharmaco 67: 287-296.

MURRAY HW, BERMAN JD, DAVIES CR, SARAVIA NG (2005). Advances in leishmaniasis. Lancet 366: 1561-77.

MURTY KS, RAO DN, RAO DK, MURTY LBG (1978). A preliminary study on hypoglycaemic and anti-hyperglycaemic effects of Azadirachta indica. Indian J Pharmacol 10: 247-250.

NWAKA S, HUDSON A (2006). Innovative lead discovery strategies for tropical diseases. Nat Rev Drug Discov 5: 941-955.

PARIDA MM, UPADHYAY C, PANDYA G, JANA AM (2002). Inhibitory potencial of neem (Azadirachta indica Juss) leaves on Dengue virus type-2 replication. J Ethnopharmaco 79: 273-278.

REILLY TP, BELLEVUE FH, WOSTER PM, SVENSSON CK (1998). Comparison of the in vitro cytotoxicity of hydroxylamine metabolites of sulfamethoxazole and dapsone. Biochem Pharmacol 55: 803-810.

ROSA MSS, MENDONÇA-FILHO RR, BIZZO HR, RODRIGUES IA, SOARES RMA, SOUTO-PADRÓN T, ALVIANO CS, LOPES AHCS (2003). Antileishmanial activity of a linalool-rich essential oil from Cróton cajucara. Antimicrob Agents Ch 47: 1895-1901. 
ROY A, SARAF S (2006). Limonoids: overview of significant bioactive triterpenes distributed in plants kingdom. Biol Pharm Bull 29: 191-201.

SANTOS AO, UEDA-NAKAMURA T, FILHO BPD, JÚNIOR VFV, PINTO AC, NAKAMURA CV (2008). Effect of brazilian copaíba oils on Leishmania amazonensis. J Ethnopharmaco 120: 204-208a.

SANTOS DO, COUTINHO CER, MADEIRA MF, BOTTINO CG, VIEIRA RT, NASCIMENTO SB, BERNARDINO A, BOURGUIGNON SC, CORTE-REAL S, PINHO RT, RODRIGUES CR, CASTRO HC (2008). Leishmaniasis treatment-a challenge that remains: a review. Parasitol Res 103: 1-10b.

SHUMUTTERER H (2002). The neem tree Azadirachta indica A. Juss. and other meliaceous plants. $2^{\text {nd }}$ ed., International print-o-pac limited. Munbai, 893pp.
SOARES-BEZERRA RJ, LEON L, GENESTRA M (2004). Recentes avanços da quimioterapia das leishmanioses: moléculas intracelulares como alvo de fármacos. Rev Bras Cienc Farm 40: 139-149.

TAHIR AE, SATTI GMH, KHALID SA (1999). Antiplasmodial activity of selected sudanese medicinal plants with emphasis on Maytenus senegalensis (Lam.) Exell. J Ethnopharmaco 64: 227-233.

TEIXEIRA MCA, SANTOS RJ, SAMPAIO RB, PONTES-DE-CARVALHO L, DOS - SANTOS WLC (2002). A simple and reproducible method to obtain large numbers of axenic amastigotes of different Leishmania species. Parasitol Res 88, 963-968.

YANES A, FINOL HJ, HASEGAWA M (2004). Effects of Azadirachta indica and Melia azedarach (Meliaceae) extracts from leaves on Trypanossoma cruzi growth and ultrastructure. J Submicrosc Cytol Pathol 36(2): 149-154. 